\title{
Percutaneous dilational tracheotomy in liver transplant recipients
}

\author{
A Kundakci Ozdemirkan*, Z Ersoy, P Zeyneloglu, E Gedik, A Pirat, M Haberal \\ From ESICM LIVES 2015 \\ Berlin, Germany. 3-7 October 2015
}

\section{Introduction}

Liver transplant recipients (LTR) may require percutaneous dilational tracheotomy (PDT) during the immediate postoperative period or later because of need for prolonged mechanical ventilation or airway issues. However, despite the increased risk of bleeding and infections, there is little data regarding the safety and effectiveness of PDT in LTRs.

\section{Objectives}

The aim of this study was to evaluate the safety and effectiveness, in terms of changes in oxygenation and lung compliance, of PDT in LTRs.

\section{Methods}

We reviewed the data of liver transplant recipients who underwent percutaneous dilational tracheotomy in Baskent University Hospital between January 2010 and March 2015. Collected data included demographics (age, sex, body weight, length); etiology of chronic liver failure; comorbidities; Child, Model for End Stage Liver Disease (MELD), acute physiology and chronic health evaluation II (APACHE II), and sequential organ failure assessment (SOFA) scores; length of hospitalization and mechanical ventilation; etiology of acute respiratory failure; pre-PDTPlatelet count and international normalized ratio (INR) values; partial pressure of arterial oxygen to fractional inspired oxygen ratio (P/F), and pulmonary compliance. Pre- and post-PDT values were compared using Wilcoxon test.

\section{Results}

Out of 136 LTRs 16 required PDT during the study period. All PDTs were performed by experienced intensivists and under bronchoscopic guidance using Percutwist or Ciaglia techniques. The mean age was $35.4 \pm 16.5$ years and mean body mass index was $25.5 \pm 6.0 \mathrm{~kg} / \mathrm{m}^{2}$. The mean Child and MELD scores were $10.5 \pm 1.9$ and $23.5 \pm 7.7$, respectively. The mean APACHE II on admission was $25.4 \pm 11.9$ Pre-PDT platelet count and INR were $47000 \pm 41000$ per $\mu \mathrm{l}$ and $2.0 \pm 0.8$, respectively. The indication for PDT was prolonged mechanical ventilation for all patients. The etiology of acute respiratory failure was most commonly extrapulmonary (\%87.5). The mean interval from transplantation to PDT was $355 \pm 870$ days. The only major complication noted was left-sided pneumothorax in one patient. Six patients had minor, sel-limiting bleeding from the tracheotomy site on the first day of post-PDT. There were no significant differences between pre-PDT and postPDT P/F ratios (261 \pm 203 vs $264 \pm 132$; p:0.534). However pre- and post-PDT pulmonary compliances were significantly different $\left(0.02 \pm 0.02 \mathrm{~L} / \mathrm{cmH}_{2} \mathrm{O}\right.$ vs $0.03 \pm 0.02$ $\left.\mathrm{L} / \mathrm{cmH}_{2} \mathrm{O}, \mathrm{p}: 0.002\right)$. The number of patients who required sedation significantly decreased after PDT (7 versus 1 , $\mathrm{p}=0.03)$.

\section{Conclusions}

When performed by experienced intensivists using bronchoscopic guidance PDT is safe in LTR. PDT may also improve lung mechanics and decrease the need of sedation in these patients.

Published: 1 October 2015

doi:10.1186/2197-425X-3-S1-A905

Cite this article as: Kundakci Ozdemirkan et al:: Percutaneous dilational tracheotomy in liver transplant recipients. Intensive Care Medicine Experimental 2015 3(Suppl 1):A905. 